\title{
Will physicians be able to recover the empathy we used to have with patients?
}

In order to discuss this subject, which is related to the inadequate behaviors of several physicians in current medical practice, it is necessary to present the actions that have led to habit modifications when facing the totally uncertain situations encountered in the medical profession. In addition, we can clearly see that there are many deviations from one of the fundamental principles of medicine, which is based on helping and caring for patients, above any other interest.

I believe that, in this situation, it is essential that we, physicians, analyze possible answers and patient satisfaction in current medical practice. There is no doubt that changes in medicine have been increasing faster and faster; however, it is regrettable that they have been based solely on science, given that humanism has progressively diminished in actions taken by physicians. Moreover, it is not possible to preserve the art that has always been present in medicine, because it is being swept away by mercantilism, technology, utilitarianism, etc.

It is worth noting that science has led us to many significant advances, especially related to the cure of severe diseases, even for extremely uncommon ones.

Nevertheless, it is absolutely necessary for physicians to keep in mind that medicine is not merely a science, but should be accompanied by humanism, which is an essential pillar in order to maintain an appropriate behavior with patients at all times. The presence of art in medicine allows us to perform the actions we take at all times and when caring for patients, both for adults and for children and their parents.

In addition, it is completely necessary that physicians know that our profession is an art based on science, quoting Karl Jasper, physician and philosopher: "medical art, unlike other art forms, aims at the restoration of a natural state, through science, but also through consolation, compassion, help".

Every inadequate action taken by physicians mainly leads to a major crisis of confidence in patients as to their relationship with physicians. Unfortunately, this is clearly increasing, rather than improving. Many professionals do not keep in mind that medical practice goes beyond scientific boundaries, and these actions displace humanism, one of the pillars of medicine since time immemorial. If this situation does not change, we will face a tragedy, because medical practice will be getting further and further away from the patient.

Physicians could improve their relationship with patients and, to that end, they can learn through adequate knowledge of what should be done in medical practice. In order to do so, it is critical that this learning starts at university, during the residency program, and also in the first years of medical practice. Multiple pieces of evidence indicate that these skills can be learned in an early manner, thus ensuring better results. One of the main problems of medical education nowadays is that there is a disproportionate amount of scientific information, which will undoubtedly be useless. In addition, they will end up being those kinds of people who "say they know, but they do not know," which is a big mistake and, instead of helping patients, they will harm them.

Moreover, I would like to point out an extremely important action when being in contact with patients: altruism, one of the ancient medical principles, and one of the most relevant as well. Altruism means to pursue the wellbeing of others, even at the expense of our own, and also foster responsibility and motivation in order to provide the best care, and maintain a desire to serve others with honor and respect. This is extremely important because, in my opinion, current physicians do not keep altruism in mind, since they are scarcely trained on social skills and are not able to relate with their patients as human beings. Trousseau left us these words: "the worst physician these days is the one who exudes science and barely masters the art of medicine. Helping people heal is purely and simply an art".

I will address empathy, which is one of the most expected actions in the patient-doctor relationship. When we discuss empathy, its concept is not always clearly defined, although it is strongly associated with a feeling of identification with something or someone. But it is also extremely important to mention the ability empathy has to share the patients' feelings, which is therefore a blend of adequate information, kindness, and a sensitive regard. Otherwise, the term empathy refers to the mental ability of effectively 
putting yourself in somebody else's shoes, which is critical in the patient-doctor relationship. In addition, it will allow us to be able to understand someone else's mind, know what they may be going through, and what they will feel and worry about.

Among other effects, it is important to highlight that empathy allows to achieve an adequate balance between scientific knowledge and care provided to patients and children's parents. This indicates that, at all times, there are actions that should always be present in the doctor-patient/ parent relationship, by emphasizing the importance of emotions. It is critical that this action is shared with students and physicians just starting their career. By keeping emotions in mind, they will accompany them from an early stage and, therefore, they will incorporate what they must know and do as physicians. This will allow them to maintain it forever in medical practice.

The importance of developing empathy with patients is much needed these days, given that there is an important crisis of confidence in patients as to their relationship with doctors. We should consider that a lack of trust breaks off any relationship between people.

Developing empathy between the physician and the patient not only favors the patient, but also the physician, given that it increases diagnostic accuracy, and a good clinical judgment allows to adequately assess the need for certain tests and, also, to prescribe the correct medications. This is what patients and their parents expect, since this will lead to their satisfaction, ensuring great trust in the doctor.

Finally, I would like to highlight the importance of ethics in every action we take as physicians. In this regard, I point out the question that was published in The Lancet 27 years ago: How much ethics is needed to make a good doctor?
The answers encompassed three actions which are necessary to maintain ethics at all times in our profession, which were:

Motivation: being interested in the patient and feeling satisfaction by helping them.

Judgment: assessment, advice, and patientcentered decisions.

Empathy: a blend of adequate information, kindness, and a sensitive regard.

We shall always maintain these actions in every daily activity we undertake as part of medical practice. In this way, we will have an adequate relationship with patients and their parents, and they will receive help and care, in the context of a medical practice that respects ethics.

\section{José María Ceriani Cernadas}

Editor-in-chief

http: / / dx.doi.org/10.5546/ aap.2020.eng.298

To cite: Ceriani Cernadas JM. Will physicians be able to recover the empathy we used to have with patients? Arch Argent Pediatr 2020;118(5):298-299.

\section{REFERENCES}

- Brewin TB. Search Results. How much ethics is needed to make a good doctor? Lancet. 1993; 341(8838):161-163.

- Suchman AL(1), Markakis K, Beckman HB, Frankel R. Search Results Web results. A model of empathic communication in the medical interview. JAMA. 1997; 277 (8):678-82.

- Preston SD, de Waal FBM. Empathy: its ultimate and proximate bases. Behav Brain Sci. 2002; 25(1):1-20.

- Borrell Carrió F. Empathy, a core value in clinical practice. Clinical Medicine, On-line September, 2009.

- Riess H.Empathy in medicine-a neurobiological perspective. JAMA. 2010; 304(14):1604-5.

- Musso CG, Enz PA. Art as an educational tool in medicine. Arch Argent Pediatr. 2014; 112(6):494-5.

- Basch E. Patient-Reported Outcomes - Harnessing Patients' Voices to Improve Clinical Care. NEJM, January 12, 2017.

- Ceriani Cernadas JM. Editorial, La pérdida de la ética y el humanismoenla profesión médica ¿esunautopíarecuperarlos? Editorial, Arch Argent Pediatr. 2017; 115(6):522-3.

- Corrigan-Curay JD, Sacks L, Woodcock J. Real-world tests and real-world data to assess the safety and effectiveness of medications. JAMA. 2018; 320(9):867-8. 